\title{
OPTIMALISASI PROSES CARGODORING PADA TERMINAL PETI KEMAS BANJARMASIN
}

\section{CARGODORING OPTIMALIZATION PROCESS AT BNJARMASIN CONTAINER PORT}

\author{
Vivian Karim Ladesi ${ }^{a 1}$, Salman Ridho ${ }^{\text {b,2 }}$ \\ ${ }^{1}$ Prodi D III Transportasi, Fakultas Teknik - Universitas Negeri Jakarta \\ ${ }^{2}$ Prodi D III Transportasi, Fakultas Teknik - Universitas Negeri Jakarta1* \\ 1karim_ladesi@unj.ac.id, 2yamhasalman@gmail.com. \\ *corresponding e-mail: admind3transportasi@unj.ac.id
}

\begin{abstract}
Transportation is a means for humans to reach their destination, from A to B. Indonesia as an archipelagic country thus transportation plays an important role for viability as well as for civilization as a nation. A good port according to "National law regarding to port number 17 of 2008", is equipped with seafare safety facilities and supporting activities and institute for intra and intermodal transportation. One of activities at port is Cargodoring, which is a process of moving goods from the warehouse to apron that is carried by transport aids. Observations only cover a few aspects, one of which is the long turn-around-time of the head truck during cargodoring operation. Based on observations at Banjarmasin Container Terminal, PT Pelindo III Persero, South Borneo branch, issues can be found at facilities is sluggish turn-around-time trucks at cargodoring operation, resulting delays to ship departure time. To find out how long it takes for a cargodoring. A direct observation route is taken and also take part at the operation process. With the increase in operational speed of carrier equipments and truck, adjustments is needed to the condition of the port facilities such as the road within the port itself. Knowing the actual time of the process for cargodoring, through direct observation combined with on hands experience and quantify the times required. Results are in the time spectrum to find the best results to be applied in the real world.
\end{abstract}

Keywords : Cargodoring, Port, Head Truck

\begin{abstract}
ABSTRAK
Transportasi merupakan moda sebagai means bagi manusia atau individu untuk mencapai tujuan, satu titik menuju satu titik tujuan lainnya. Indonesia merupakan negara kepulauan maka transportasi bermain peran penting bagi kelangsungan hidup serta bermasyarakat, berbangsa, dan bernegara. Pelabuhan yang baik menurut Undang Undang kepelabuhanan nomor 17, tahun 2008, dilengkapi dengan fasilitas keselamatan pelayaran dan kegiatan penunjang pelabuhan serta sebagai tempat perpindahan intra dan antar moda transportasi. Kegiatan pada pelabuhan berupa perpindahan kargo Cargodoring, yaitu proses pergerakan barang dari gudang atau lapangan penumpukan ke dermaga atau apron yang di bawa oleh alat bantu angkut. Pengamatan hanya mencakup beberapa aspek salah satunya pada Waktu putar head truck yang lama selama
\end{abstract}


proses cargodoring. Terminal Peti kemas Banjarmasin, PT Pelindo III Persero, cabang Kalimantan Selatan, dapat ditemukan permasalahan lambatnya turn-around-time head truck atau kegiatan cargodoring yang mengakibatkan keterlambatan pada waktu keberangkatan atau departure kapal. Untuk mengetahui berapa lama waktu yang dibutuhkan head truck untuk melakukan cargodoring. Penuilis melakukan Pengamatan langsung secara terlibat. Dengan melakukan perbaikan pada lintasan didalam pelabuhan untuk dapat mendukung peningkatan kecepatan pada chassis dan juga gerak pada alat angkat pada lapangan penumpukan atau container yard, yang dapat menghasilkan produktivitas yang lebih baik pada kegiatan bongkar dan muat.

Kata kunci : Cargodoring, Pelabuhan, Head Truck

\section{A. Pendahuluan}

Trasnportasi perairan memainkan peran penting sebagai penyedia moda bagi kegiatan manusia, baik sebagai moda penyebrangan individual dan juga moda pendistribusian logistik, mengingat Indonesia merupakan negara kepulauan. Pelabuhan memainkan peranan penting dalam transportasi perairan dan juga perekonomian negara sebagai salah satu penyumbang pertumbuhan ekonominya. Pelabuhan adalah tempat yang terdiri dari daratan dan perairan di sekitarnya dengan batas-batas tertentu sebagai tempat kegiatan pemerintah dan kegiatan ekonomi, dipergunakan sebagai tempat kapal bersandar, naik turun penumpang dan/atau bongkar muatan barang, ataupun sebagai tempat perbaikan sementara, jika pelabuhan terkait menyediakan jasa. "Didalam suatu lingkup pelabuhan, pengukuran performa tidak hanya sebatas alat atau metode sebagai alat ukur bagi operasional pelabuhan, tetapi juga merupakan input yang penting sebagai sumber informasi pelabuhan secara regional dan juga nasional. Secara tradisional, performa pelabuhan selalu bervariasi dalam evaluasi secara pengukuran produktifitas melalui perhitungan cargo handling selama berth melalui satu faktor produktifitas atau melalui komparasai secara aktual melalui trhoughput optimal dalam waktu tertentu", Dikutip dari artikel yang ditulis oleh, Tengfei Wang, Dong-Wong Song serta Kevin Cullinae yang berjudul Container port production efficiency: a comparative study of DEA and FDH approaches.

Kegiatan stevedoring merupakan proses kegiatan bongkar dan muat kapal menggunakan alat bantu dari sisi darat dan atau kapal yang menggunakan prinsip katrol untuk menaik dan menurunkan barang ke atas dan atau dalam kapal. Barang yang akan dinaikkan ke kapal atau di turun kan dari kapal akan memperlukan proses Haulage atau Cargodoring, yaitu proses pergerakan barang dari gudang atau lapangan penumpukan ke dermaga atau apron yang di bawa oleh alat bantu angkut. 
Pada saat kapal sandar di dermaga, proses bongkar muat dilakukan dimulai dari penyandaran kapal ke dermaga lalu proses bongkar dan muat barang dari kapal dan ke kapal bisa dimulai. dapat ditemukan permasalahan berupa lambatnya turnaround-time head truck atau kegiatan cargodoring yang mengakibatkan keterlambatan pada waktu keberangkatan atau departure kapal, hal ini disebabkan oleh lambatnya kecepatan rata rata unit truck cargodoring karena jalan yang tidak baik, serta proses penumpukan yang lambat akibat bercampurnya waktu kegiatan operasi delivery dan receiving pada lapangan penumpukan.

\section{B. Metode Penelitian}

Metode pembahasan merupakan cara yang digunakan untuk memaparkan pembahasan mengenai permasalahan yang telah dipilih penulis. Metode pembahasan yang digunakan melalui kuantitatif, yaitu dengan cara melihat waktu kinerja cargodoring di Terminal Peti kemas Banjarmasin untuk mengetahui delta waktu terbaik dan waktu yang sebenarnya dilapangan, serta menenetukan waktu optimal.

\section{Hasil dan Pembahasan}

Metode pembahasan merupakan cara yang digunakan untuk memaparkan pembahasan mengenai permasalahan yang telah dipilih penulis. Metode pembahasan yang digunakan melalui kuantitatif, yaitu dengan cara melihat waktu kinerja cargodoring di Terminal Peti kemas Banjarmasin untuk mengetahui delta waktu terbaik dan waktu yang sebenarnya dilapangan, serta menenetukan waktu optimal. Rumusan yang ditentukan berdasarkan darta yang ada yaitu kecepatan, jarak dan waktu, dengan satuan jarak dalam (M) Meter dan waktu serta satuannya dalam detik atau Second (S). Rumus untuk mensetarakan variable serta menemukan waktu yang dibutuhkan untuk menempuh jarak.

a. Tabel data produksi Head Truck

Data yang diperoleh secara langsung oleh penulis pada saat melakukan pengamatan langsung berpartisipasi di lapangan pada Terminal Peti kemas Banjarmasin. Berikut adalah hasil pengamatan dan pencatatan selama melakukan pengamatan dengan ketentuan waktu dalam sekon sebagai berikut;

a. Dalam Pencatatan dilakukan selama waktu kegiatan berlangsung.

b. Pencatatan dilakukan selama satu satu shift kerja atau 8 jam

Berikut ini merupakan tabel data dari head truck selama melakukan pekerjaan baik bongkar atau (D) dan memuat atau (L), data dalam tabel berisi tentang waktu dari proses cargodoring berupa 
lift on dan lift off waktu berputar dari dermaga menuju lapangan penumpukan atau sebaliknya dalam bentuk kolom "Travel" serta waktu "idle" atau waktu yang tidak produktif dalam proses, serta tipe dan jumlah petikemas yang di bawa, trasnlasi kedalam bentuk tabel sepertiberikut;

\begin{tabular}{|c|c|c|c|c|c|}
\hline Litat on & Fravel & Liat ot & Thatel & Kile & Tipe Peti Kemas \\
\hline 30 & 640 & 50 & 830 & 841 & 40 Feet Kosane \\
\hline 42 & 538 & 58 & 920 & 727 & 40 Feet Konong \\
\hline 40 & 755 & 47 & 100 & 625 & 40 Ftet R Kosonge \\
\hline 30 & & 53 & & & 20 Feet Kowons \\
\hline 31 & 308 & 59 & 300 & 599 & 20 Feet Kosonef \\
\hline 120 & $9 / 2$ & 433 & 700 & 582 & 20 Fent OWD \\
\hline
\end{tabular}

\begin{tabular}{|c|c|c|c|c|c|}
\hline Lia on & Trasel & Litat of & Travel & Wale & Tige Peti Kemas \\
\hline 42 & & $\pi$ & & & 20 Feert Penit \\
\hline 31 & Ins & 65 & 187 & 521 & 20 Feet Penah \\
\hline 64 & & 20 & & & 20 Feet Penih \\
\hline 43 & 977 & 56 & 590 & 765 & 20 Feet Pendi \\
\hline 44 & 684 & 60 & 650 & 214 & so Feet R Fetwib \\
\hline 35 & & 45 & & & 20 Feet Pemih \\
\hline 67 & 364 & 77 & 300 & 345 & 20 Feer Penuh \\
\hline 92 & & 35 & & & 20 Foot R Femuh \\
\hline 50 & 430 & 67 & 440 & 634 & 20 Foet B Penuil \\
\hline
\end{tabular}

\begin{tabular}{|c|c|c|c|c|c|}
\hline Liff on & Travel & Lift off & Trasel & Tdle & Tipe Pets Kemas \\
\hline 259 & 793 & 379 & 790 & 333 & $\begin{array}{l}20 \text { Feet OVD } \\
\text { Kosong }\end{array}$ \\
\hline 358 & & 50 & & & $\begin{array}{l}\text { Thapa ISO } \\
\text { Penuil }\end{array}$ \\
\hline 498 & 389 & 59 & 577 & 213 & $\begin{array}{l}\text { Tangli tso } \\
\text { Penuh }\end{array}$ \\
\hline 309 & & 83 & & & $\begin{array}{l}\text { Tenpatso } \\
\text { Koseng }\end{array}$ \\
\hline 330 & 620 & $\infty$ & 605 & 470 & $\begin{array}{l}\text { Tapio iso } \\
\text { Koseng }\end{array}$ \\
\hline 60 & 429 & 59 & 414 & 512 & 40 Feet Penulh \\
\hline
\end{tabular}

\begin{tabular}{|c|c|c|c|c|c|}
\hline Lift on & Travel & Lift off & Travel & Idle & Tipe Pets Kenas \\
\hline 84 & & 133 & & & 20 Feet Pensh \\
\hline 60 & 153 & 115 & 150 & 674 & 20 Feet Penath \\
\hline 62 & & 143 & & & 20 Feet Penids \\
\hline 41 & 377 & 142 & 350 & 521 & 20 Feet Penub \\
\hline 133 & & 120 & & & 20 Feet Penidus \\
\hline 95 & 356 & 116 & 344 & 422 & 20 Feet Pening \\
\hline$\overline{87}$ & & 164 & & & 20 Feet Pends \\
\hline 58 & 323 & 177 & 332 & 509 & 20 Feet Peanh \\
\hline 64 & 1 & 109 & & & 20 Feet Penulh \\
\hline 62 & 398 & 104 & 371 & 739 & 20 Feet Penis \\
\hline 42 & & 98 & & & 20 Feet Penich \\
\hline 4 & 24 & 104 & 264 & 501 & 20 Feet Penul \\
\hline
\end{tabular}

\begin{tabular}{|c|c|c|c|c|c|}
\hline Lift on & Travel & Lift off & Travel & Idle & Tipe Peti Kemas \\
\hline 87 & & 100 & & & 20 Feet Penuh \\
\hline 93 & 226 & 189 & 220 & 935 & 20 Feet Penuh \\
\hline 63 & & 97 & & & 20 Feet Penuh \\
\hline 59 & 232 & 105 & 240 & 481 & 20 Feet Penuh \\
\hline 86 & & 80 & & & 20 Feet Penuh \\
\hline 123 & 272 & 84 & 280 & 513 & 20 Feet Penuh \\
\hline 56 & & 60 & & & 20 Feet Penuh \\
\hline 49 & 493 & 135 & 401 & 621 & 20 Feet Penuh \\
\hline 56 & & 104 & & & 20 Feet Penuh \\
\hline 43 & 335 & 147 & 408 & 745 & 20 Feet Penuh \\
\hline 37 & & 114 & & & 20 Feet Penuh \\
\hline 52 & 656 & 143 & 710 & 643 & 20 Feet Penuh \\
\hline 37 & & 162 & & & 20 Feet Penuh \\
\hline 114 & 493 & 148 & 500 & 436 & 20 Feet Penuh \\
\hline 146 & & 165 & & & 20 Feet Penuh \\
\hline 48 & 380 & 137 & 390 & 745 & 20 Feet Penuh \\
\hline & & & & & \\
\hline
\end{tabular}

\begin{tabular}{|c|c|c|c|c|c|}
\hline Lift en & Travel & Lift off & Travel & Idiste & Tipe Peti Ketwail \\
\hline 222 & & 28 & & & 20 Feet Kotont \\
\hline 105 & 185 & 22 & 150 & 643 & 20 Feet Kosong \\
\hline 125 & & 33 & & & 20 Feet Kosong \\
\hline 135 & 577 & 36 & 523 & $\$ 65$ & 20 Feet Kesoug \\
\hline 138 & | & 33 & & & 20 Feet Konones \\
\hline 163 & 380 & 40 & 273 & 534 & 20 Feet Kosoug \\
\hline 119 & & 36 & & & 20 Feet Kosong \\
\hline 103 & 338 & 30 & 332 & 731 & 20 Feet Kononge \\
\hline 154 & & 37 & & & 20 Feet Kowotes \\
\hline 108 & 377 & 45 & 351 & 745 & 20 Feet Kosong \\
\hline 104 & & 77 & & & 20 Feet $\mathrm{R}$ Kosong \\
\hline 144 & 364 & 49 & 334 & 734 & 20 Feet R Kosone \\
\hline 119 & & 80 & & & 20 Feet Kosoug \\
\hline 153 & 413 & 83 & 452 & 345 & 20 Feet Kosons \\
\hline 178 & & 67 & & & 20 Feet Kosong \\
\hline 137 & 457 & 66 & 482 & 432 & 20 Feet Kosong \\
\hline
\end{tabular}

\begin{tabular}{|c|c|c|c|c|c|}
\hline Lif on & Trwel & Lifl off & Travel & the & Tipe Petit Kemas \\
\hline 256 & & 48 & & & 20 Feet Kosous \\
\hline 248 & 268 & 68 & 261 & 564 & 20 Feet Konong \\
\hline 146 & & 59 & & & 20 Feet Kosoag \\
\hline 135 & 308 & 38 & 292 & 643 & 20 Feet Koocng \\
\hline 128 & & 57 & & & 20 Feet Kosong \\
\hline 153 & 496 & 33 & 471 & 474 & 20 Feet Koscas \\
\hline 193 & & 36 & & & 20 Feet Kowong \\
\hline 179 & 410 & 58 & 366 & 743 & 20 Feet Kosong \\
\hline 156 & & 46 & & & 20 Feet $R$ Kosone \\
\hline 187 & 340 & 44 & 321 & 454 & 20 Feet R Kosong \\
\hline
\end{tabular}




\begin{tabular}{|c|c|c|c|c|c|}
\hline Left ce & Tratel & Laf off & Travel & talie & Tipe Fett Kemas \\
\hline 36 & 527 & 45 & 521 & 642 & 40 Feet $\mathrm{R}$ Kosoun \\
\hline 95 & 500 & 62 & 465 & 634 & 40 Feet R Konong \\
\hline 50 & & 35 & & & 20 Feet Kosong \\
\hline 72 & 262 & 48 & 289 & 754 & 20 Feet Kenons \\
\hline 90 & 627 & 55 & 206 & 453 & 40 Feet Kobcrat \\
\hline 35 & & 56 & & & 20 Feet Kosoug \\
\hline 23 & 408 & 3 & 377 & 632 & 20 Feet Koucas \\
\hline 27 & & 45 & & & 20 Feen Kosons \\
\hline 30 & 137 & 61 & 114 & 745 & 20 Feet Konches \\
\hline 23 & & 67. & & & 20 Feet Kosong \\
\hline 34 & 402 & 66 & 420 & 865 & 20 Feet Koscag \\
\hline 49 & & 47 & & & 20 Feet Konsng \\
\hline 46 & 352 & 47 & 301 & 654 & 20 Feet Konong \\
\hline Lift on & Travel & t.ift off & Trmel & tdle & Tipe Peti Kemas \\
\hline 110 & & 29 & & & 20 Feet Kesousg \\
\hline 103 & 334 & 27 & 317 & 753 & 20 Feat Kesoing \\
\hline 105 & & 80 & & & 20 Feet Kencens \\
\hline 32 & 349 & 89 & 334 & 647 & 20 Feet Kescong \\
\hline 46 & & I3 & & & 20 Feet Koacieng \\
\hline 114 & 463 & 67 & 429 & 234 & 20 Feet $\mathrm{K}$ incerns \\
\hline 146 & 307 & 33 & 348 & 324 & 40 Feet Kowcrag \\
\hline 59 & 408 & 57 & 399 & 546 & 49 Feet Kescenst \\
\hline 87 & & 61 & & & 20 Feet Koscing \\
\hline 109 & 389 & 51 & $35 ?$ & 465 & 20 Feet $K_{\text {oroseng }}$ \\
\hline
\end{tabular}

\begin{tabular}{|c|c|c|c|c|c|}
\hline Lift on & Travel & Lift off & Travel & Idle & Tipe Peti Kemas \\
\hline 45 & & 44 & & & 20 Feet Kosong \\
\hline 82 & 360 & 60 & 357 & 942 & 20 Feet Kosong \\
\hline 21 & 646 & 33 & 604 & 751 & 40 Feet Kosong \\
\hline 25 & 648 & 39 & 613 & 741 & 40 Feet Kosong \\
\hline 58 & & 34 & & & 20 Feet Kosong \\
\hline 46 & 300 & 39 & 306 & 743 & 20 Feet Kosong \\
\hline 91 & & 44 & & & 20 Feet Kosong \\
\hline 95 & 314 & 67 & 304 & 754 & 20 Feet Kosong \\
\hline 95 & & 52 & & & 20 Feet Kosong \\
\hline 78 & 330 & 58 & 322 & 1053 & 20 Feet Kosong \\
\hline 68 & & 51 & & & 20 Feet Kosong \\
\hline 69 & 306 & 50 & 341 & 933 & 20 Feet Kosong \\
\hline 53 & 650 & 36 & 535 & 919 & 40 Feet Kosong \\
\hline 69 & & 68 & & & 20 Feet Kosong \\
\hline 99 & 225 & 115 & 203 & 962 & 20 Feet Kosong \\
\hline 79 & 751 & 50 & 700 & 643 & 40 Feet Kosong \\
\hline 88 & & 36 & & & 20 Feet Kosong \\
\hline 82 & 394 & 58 & 347 & 342 & 20 Feet Penuh \\
\hline 80 & & 34 & & & 20 Feet Penuh \\
\hline 70 & 420 & 24 & 388 & 611 & 20 Feet Penuh \\
\hline & & & & & \\
\hline
\end{tabular}

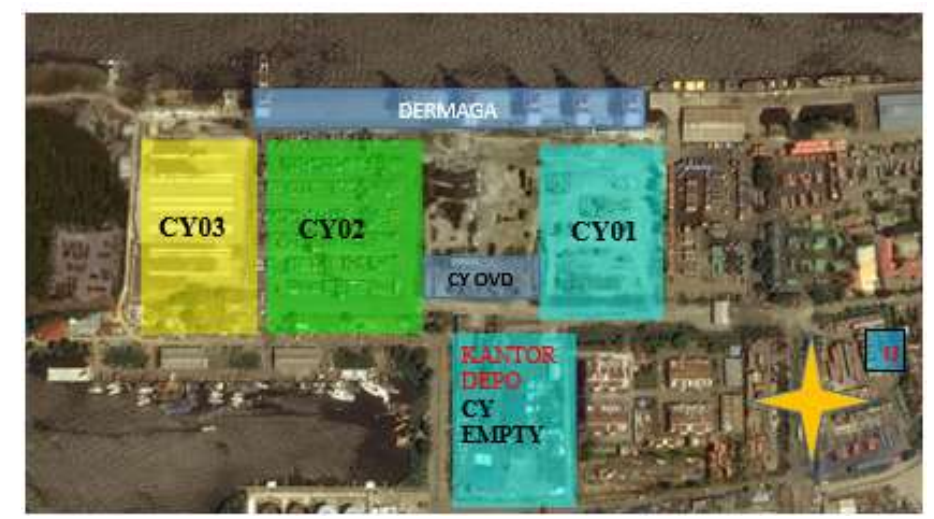

Pada penampakan ditunjukan bahwa lapangan penumpukan atau CY (Container Yard) terbagi menjadi Empat yaitu;

a. CY 1, lapangan penumpukan satu merupakan tempat penumpukan khusus untuk peti kemas bermuatan penuh untuk dimuat ke kapal. Lapangan petikemas memiliki lima blok dengan kode H-I-J-K-L, .dan Tabel data produksi Head Truck merupakan pencatatan langsung oleh penulis pada saat melakukan observasi langsung di lapangan di Terminal Petikemas Banjarmasin. masing masing blok memiliki enam slot dan tiga puluh empat baris dan dibatasi maksimal empat tumpukan vertikal dan untuk peti kemas berukuran 40 feet dikhususkan pada blok L. 
b. CY 2, pada lapangan penumpukan dua merupakan lapangan yang di khususkan untuk petikemas bongkaran dari kapal yang datang. CY dua juga memiliki dua blok khusus untuk petikemas refrigerated pada blok F-G, serta blok G juga di khusus kan untuk petikemas 40 feet, dengan skema blok A-B-C-D-E-F-G yang memiliki spesifikasi penumpukan yang sama dengan CY 1 .

c.CY 3, lapangan penumpukan 03 merupakan lapangan penumpukan yang di bangun khusus untuk menampung peti kemas bermuatan dan juga kososng jika pada CY 2 dan CY Empty sudah tidak dapat menampung peti kemas. Dengan skema blok M-N-O-P-Q yang memiliki enam slot dan tiga puluh empat baris dan dibatasi maksimal empat tumpukan vertikal serta blok M difokuskan untuk menumpuk peti kemas 40 feet.

d. CY Empty, di tempatkan khusus untuk menempatkan peti kemas kosong dengan penempatan berbeda dengan skema CY lainnya melainkan memadatkan pada sisi kanan dan kiri daripada jalur keluar masuk CY Empty dan penumpukan peti kemas vertikal maksimal empat tumpuk.

e.CY OVD, merupakan CY yang di khususkan untuk menumpuk peti kemas khusus seperti flat rack dan tangki ISO dengan ketentuan setiap penempatan flat rack masing masing berjarak 6 meter dari sisi samping dan tidak diperbolehkan untuk ditumpuk kecuali flat rack kosong. Untuk tangki ISO diberlakukan jarak 6 meter penempatan dari sisi samping sementara untuk penupukan diperbolehkan setinggi empat tumpukan vertikal. Pada lapangan penumpukan diberlakukan alur berkendara untuk kendaraan yang begerak di dalam pelabuhan, alur ini dapat di perhatikan pada gambar dibawah ini;

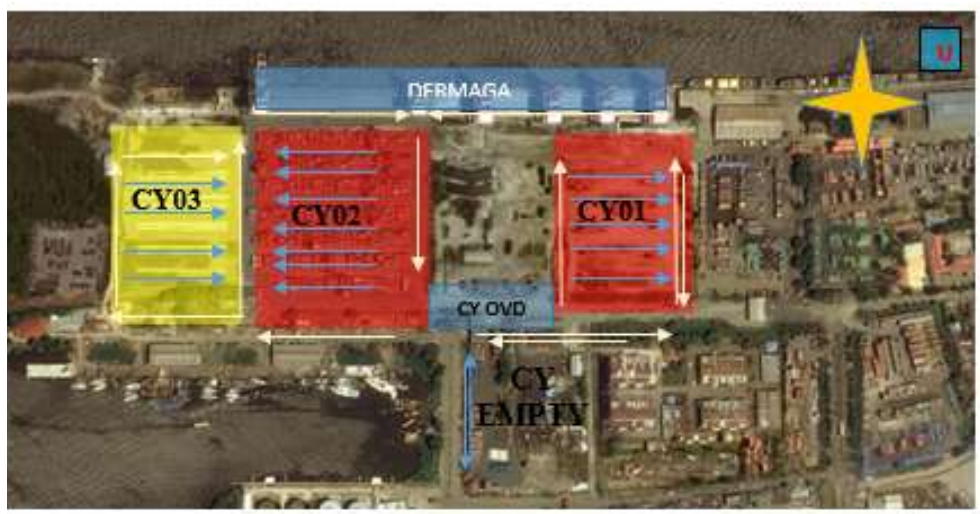

pada gambar terdapat panah dengan warna dan ketentuan sebagai berikut;

a.Panah putih, untuk alur kendaraan yang bermaksud untuk begerak untuk 
melakukan kegiatan dari dermaga ke sisi lapangan atau berputar untuk keluar dari dalam pelabuhan.

b. Panah biru, dimaksudkan untuk head truck yang akan melakukan lift on dan lift off pada CY.

Rumusan yang ditentukan berdasarkan darta yang ada yaitu kecepatan, jarak dan waktu, dengan satuan jarak dalam (M) Meter dan waktu serta satuannya dalam detik atau Second (S).

Rumus untuk men-setarakan variable, serta menemukan waktu yang dibutuhkan untuk menempuh jarak, adalah konversi kecepatan dari Kilomter per Jam (KpJ) menjadi Meter per detik $(\mathrm{MpS})$. Kemudian dengan hasil konversi kecepatan ditemukannya waktu yang dibutuhkan untuk menempuh jarak, dari hasil inilah yang dapat di temukan waktu optimal sebenarnya.

$$
\frac{K m}{J a m}=\frac{M}{K m} \times \frac{J a m}{\text { Detik }}
$$

Keterangan; $\frac{K M}{J a m}$ adalah kecepatan sebenarnya pada head truck, makan untuk mendapatkan konversi kecepatan dari $\mathrm{Km} / J a m$ menjadi Meter/Detik (S).

\section{Simpulan}

Berdasarkan pengamatan partisipan langsung dari lapangan, dapat di jabarkan bahwa waktu ideal untuk sirkulasi head truck adalah 13 menit. Waktu tersebut didapatkan dengan dasar, Lift On dari Container crane (CC) sampai head truck kembali melakukan Lift On di CC, dengan ketentuan jarak tempuh total 680 meter, dari kade 20 menuju blok bongkar Banjar G tanpa antrian pada alat angkat lapangan penumpukan untuk melakukan Lift Off, dan kembali. Begitu pula dengan kegiatan, head truck pada Kade 600 menuju blok muat Banjar L dan kembali ke Kade untuk melakukan Lift Off.

Perhitungan Jarak tempuh head truck dilakukan dengan adanya pengukuran jarak tempuh head truck sejauh 1.28 kilometer dengan kecepatan rata rata $20 \mathrm{kpj}$ dengan kondisi waktu kerja standar, kecepatan berikut dicapai karena faktor jalanan pelabuhan yang buruk serta antrian pada blok penumpukan;

Maka waktu asli yang didapatkan dari lapangan adalah sebagai berikut,

1360 meter $/ 5.56$ meter per detik $=$ 244.6 atau 14 menit dan 6 detik dengan tambahan rata rata waktu tunggu di alat angkat pada lapangan penupukan 12 menit, didapatkan total waktu 26 menit. Sementara dengan kondisi non-normal kerja atau 
diatas pukul 23.00, maka kecepatan bisa mencapai rata rata 33 kpj; $1360 / 9.167=$ 148.3 atau 8 menit dan 9 detik dengan tambahan rata rata waktu alat angkat lapangan penumpukan 4 menit, pada waktu berikut, maka didapatkan total waktu siklus adalah 12 menit. Pada waktu kegiatan cargodoring dilakukan dengan kecepatan rata rata di $20 \mathrm{kpj}$ maka kegiatan bongkar dan muat akan menamakan waktu sebanyak 26 menit pada kegiatan cargodoring. Sementara dengan kegiatan bongkar dan muat dengan proses cargodoring yang mencapai kecepatan rata rata 33 kpj maka, waktu cargodoring dapat di tekan sebanyak 6 menit. Jika waktu kegiatan dapat ditekan maka kinerja bongkar muat juga dapat hasil yang lebih tinggi.

\section{E. Daftar Pustaka}

Cahyaningtyas, J. (2017). Peluang dan Tantangan Pelabuhan Laut. In O. Irianto, N. Loy, M. Rusdi, L. Madu, S. Wibisono, \& J. Cahyaningtyas, Membangun Dari Laut : Industri dan Jasa Maritim Indonesia (p. 89). Yogyakarta: Aswaja Pressindo. Indonesia. (2001). Peraturan Pemerintah No. 69 tentang Kepelabuhanan Pasal 1. Jakarta: Sekretariat Negara.

Indonesia. (2001). Peraturan Pemerintah No. 69 tentang Kepelabuhanan Pasal 4. Jakarta: Sekretariat Negara.
Indonesia. (2008). Undang Undang No. 17 tentang Pelayaran. Jakarta: Sekretariat Negara.

Karsafman, T. (2004). "Operasi Terminal Khusus" Diktat Kuliah Operasi Terminal Khusus. Jakarta: DIII Transportasi Laut dan Kepelabuhannan Universitas Negeri Jakarta.

Menteri Perhubungan Republik Indonesia. (2015, 02 23). PERATURAN MENTERï PERHUBUNGAN REPUBLÏK INDONESIA NO.51 TENTANG

PENYELENGGARAAN

PELABUHAN LAUT. 2015, pp. 1-3.

Soewedono, H. (2007). Transportasi Laut Dan Pelabuhan Sebagai Sarana Vital Dan Strategis Bagi Negara Kepulauan Indonesia. Jakarta: STMT Trisakti.

Sudjatmiko, F. (1995). Pokok-Pokok Pelayaran Niaga. Jakarta: CV Akademika Pressindo.

Suyono, P. R. (2001). SHIPPING : Pengangkutan Intermodal Ekspor Impor Melalui Laut. In P. R. Suyono, SHIPPING : Pengangkutan Intermodal Ekspor Impor Melalui Laut (pp. 198 - 205). Jakarta: Penerbit PPM.

Wang, T., Song, D.-W., \& Cullinane, K. (2003). Container Port Production Efficiency : a Comparative Study of DEA and FDH Approaches. 